\title{
SOBRE EL SENTIDO IRÓNICO EN ESPAÑOL. ASPECTOS PRAGMÁTICOS Y LEXICOGRÁFICOS ${ }^{1}$
}

\author{
Carmen Marimón Llorca \\ Universidad de Alicante \\ marimon@ua.es
}

\section{RESUMEN}

La ironía es uno de los acontecimientos verhales que, en los últimos años. ha despertado mayor interés entre los lingüistas interesados en estudiar aspectos intencionales del significado. Muchas de las principales teorías pragmáticas han elaborado modelos de análisis para explicar qué mecanismos utilizamos para construir y comprender un enunciado irónico. Por su parte. la lexicografía académica ha incluido desde sus orígenes tanto el concepto como la marca «irónico» que, junto con otras como "afectivo»o "despectivo», tratan de dar cuenta de las intenciones de los hablantes. En ese espacio de convergencia entre ambas disciplinas se enmarca este trabajo cuyo objetivo último es comprender el concepto de sentido irónico en español. Para ello partiré del estudio de la transformación de la definición de «ironía» desde la primera edición del DRAE hasta la actualidad -DRAE 2001- En segundo lugar voy a intentar establecer qué clase de criterios se han utilizado para señalar una palabra o una expresión como irónica. Me interesa saber qué se entiende por sentido irónico y si es posible reconocer ese sentido en una palabra o expresión a partir de la información que nos ofrece el Diccionario. Se utilizan corpus orales y escritos para ejemplificar.

Palabras Clave: I exicografía: Pragmática; ironía: Retórica: Diccionario.

\footnotetext{
1 Este trabajo ha sido posible gracias al Proyecto de Investigación del MEC HUM2004-01318/FILO 20052008 titulado «Análisis pragmático de la ironía verbal. Tipología y aplicaciones a la enseñanza del español como lengua extranjera».
} 


\section{ABSTRACT}

Irony is a verbal phenomenon that has received a big deal of attention from linguistics interested in studying the implicit part of meaning. Most of the main Pragnatic theories have developed different models to explain the kind of mechanisms people use to produce and understand an ironic utterance. Likewise Academic Lexicography has always included on its dictionaries different marks able to give account of the speakers" intention. One of those is the mark eirony". The present work finds its sense in the space of convergence between both disciplines - Pragmatics and Lexicography- and its final aim is to understand the concept of irony in Spanish as it is presented at DRAE 2001. For this purpose, first I'll study the changes on the definition since the first edition of the Dictionary to the last -DRAE 2001- Secondly. I'll try to establish the criteria used to signal a word or an expression as ironic. I'm interested in knowing what is meant by «ironic sense" and if it is possible to recognize this sense taking the information offered by the Dictionary. Oral and Written corpora are used to show examples.

KEY WORDS: Lexicography: Praginaties: irony; Rhetoric: Dictionary.

\section{LA IRONÍA, LA PRAGMÁTICA Y EL DICCIONARIO}

1.1. Desde los orígenes de la Lexicografía hispánica y, en particular, de la Lexicografía académica, es habitual encontrar en la microestructura de los Diccionario, además de marcas consagradas a aspectos diacrónicos, diatópicos, gramaticales o técnicos, otro tipo de marcación diasistemática en la que se incluyen referencias más o menos organizadas y regulares al nivel social — vulgar, rústico—, al estilo — poético-, o a la intención - burlesca- de un determinado término ${ }^{2}$. De entre este último grupo, podemos constatar cómo las marcas diastrático/diafásicas, a pesar de las dificultades en cuanto a su selección y adjudicación, han ido, en las sucesivas ediciones del $D R A E$, sistematizándose y ajustándose a criterios y denominaciones avaladas por el conocimiento lingüístico. Así, por ejemplo, se distingue, por un lado, la variante de registro «coloquial»-que tiene que ver con el uso que de la lengua hacen los hablantes - y las variedades diastráticas, "culto», "germanía», «jergal», «rural», determinadas por el nivel social de los usuarios. Sin duda, el desarrollo de la Sociolinguiística y la consolidación de sus principios teóricos y sus métodos, han sido en buena parte responsables de la evolución de este tipo de indicaciones. Además de las referidas al llamado lenguaje poético, que, en la actualidad -me refiero al DRAE 2001 - , han quedado reducidas a «poét.» y sus correspondientes notas de uso, bajo el epígrafe «intención del hablante» tenemos un conjunto heterogéneo de marcas diasistemáticas cuya conformación a lo largo de la historia de las obras lexi-

2 Como se señala en Azorín Femández (2000), antes que en el Tesoro de Covarrubias, donde aparecen voces marcadas como «lenguaje grosero» 0 «término poético», ya en el Alfabeto primero del Diccionario nunca publicado de Francisco del Rosal se encuentran caracterizaciones diasistemáticas relativas al «origen profesional», «no urbano», «vulgar» o «infantil» de las entradas. En cuanto al estudio —particular y general- de las marcas en los diccionarios monolingües del español, se ha especializado en su estudio Cecilio Garriga (1994, 1995. 1996). Ver también para este mismo ámbito Fajardo (1996-97) y para los de aprendizaje Gutiérrez (1996). 
cográficas ha sido más variable en sus contenidos y criterios que cualquier otro tipo de marcación. No es casual que esto ocurra así, ya que estamos ante la parte menos «tangible» y sistematizable del significado, la más difícil de codificar y fijar en un diccionario en la medida en que está condicionada por la intención de un hablante en una determinada situación de uso. La marca «irón.»-que se encuentra entre ellas y que es de la que nos vamos a ocupar aquí- y todas las demás relacionadas con las intenciones de los hablantes - afectivo, despectivo, enfático, festivo o peyorativo, entre otras - son muestra del interés, ya antiguo, de la Lexicografía —recordemos los trabajos pioneros de Menéndez Pidal (1945) y de Casares (1950) - por recoger en los diccionarios los significados que tienen que ver con los hablantes y con los distintos usos que estos hacen de la lengua. En este sentido, como apuntaba Ettinger (Haensch y otros, 1982:380) hace ya algunos años, la Lexicografía ha ido por delante de la evolución de la propia Linguística al haber afirmado, con su interés por las distintas posibilidades de uso de la lengua, la heterogeneidad natural del sistema lingüístico:

Mientras las diferentes escuelas del estructuralismo y la gramática generativa transformacional partieron, de manera explícita o implícita, de una homogeneidad ficticia del sistema lingüístico, los lexicógrafos han señalado siempre las diferenciaciones dentro de una lengua y también casi siempre las han tenido en cuenta en sus trabajos prácticos

Sin embargo, en estas últimas décadas, la Lingüística ha prestado especial atención y orientado buena parte de sus trabajos precisamente a estos aspectos intencionales del significado. La concepción de la lengua como discurso, la prioridad del uso y la importancia de las funciones sociales del lenguaje son los ejes sobre los que se sitúa el modelo funcional o pragmático-textual, paradigma indiscutible hoy en día ante cualquier aproximación al lenguaje. La amplitud del objeto pragmático —estudiar la relación entre los signos y sus usuarios, según la definición original de Morris-, unido a la diversidad de tendencias que convergen en su nacimiento, ha dado lugar a que, bajo el nombre de Pragmática, se inscriba un gran número de líneas de investigación cuyo nexo es estudiar el lenguaje en su función comunicativa, y cuyo objetivo común es intentar explicar cómo los hablantes codificamos nuestras intenciones en el lenguaje. Las teorías de los Actos de habla, la Argumentación, la Relevancia, el Principio de Cooperación, la Polifonía, etc., representan algunas de esas propuestas en las que ahora, naturalmente, no nos podemos detener ${ }^{3}$, pero todas ellas se han ocupado de aspectos del significado poco atendidos hasta entonces por la Lingüística. El punto de vista pragmático se ha convertido en un componente bajo cuya perspectiva han encontrado explicación satisfactoria numerosos problemas lingüísticos de naturaleza gramatical o semántica. Al aportar la dimensión comunicativa, cuestiones en principio puramente sintácticas - como la deixis o los conectores- pero también semánticas - como la metáfora- se han convertido en realidad en cuestiones pragmáticas, pues para su resolución es imprescindible utilizar conceptos explicativos como la capacidad de procesamiento, la relación fondo-figura o los distintos niveles inferenciales, pertenecientes todos ellos a una perspectiva ampliada sobre los problemas del

\footnotetext{
${ }^{3}$ Son muy numerosas y accesibles las monografías, los diccionarios y los manuales en los que se presentan las principales teorías pragmáticas. Señalaré únicamente y puesto que este no es el objetivo de este trabajo algunas referencias imprescindibles. Reyes, 1990 y 1996, Escandell, 2000, Moeschler-Reboul, 1999, Levison 1989, Leech 1983.
} 
lenguaje que incluye las capacidades y los puntos de vista de los usuarios. Uno de los temas que interesan especialmente a la Linguística de orientación pragmática tiene que ver con lo que tradicionalmente se ha denominado el lenguaje figurado.

En efecto, si la Pragmática está interesada, entre otros aspectos, en estudiar de qué manera codificamos los hablantes las intenciones en nuestros enunciados, el estudio de la utilización del lenguaje figurado, esto es, de la metáfora, la metonimia y, en particular, del sentido irónico constituye, sin duda, una verdadera ocasión para comprender cómo el lenguaje puede, al mismo tiempo —utilizando a Ducrot (1982)--, decir y no decir, lo que en realidad sí quiere decir un sujeto enunciador y hacer, contra todo pronóstico, efectivo el proceso comunicativo. Así, cuando leemos en un artículo de prensa que los franceses pretenden retrasar a «calendas griegas» una determinada decisión, cuando alguien exclama «lo que me hace gracia» para empezar a hablar de un determinado asunto o cuando mi interlocutor me espeta un «y un jamón con chorreras» después de ofrecerle una explicación, algún mecanismo que forma parte de mi competencia comunicativa se pone en funcionamiento para advertirme, como mínimo, de que no tengo por qué saber el computo temporal de las calendas para entender a los franceses, que lo que va a decir el hablante a continuación en realidad no le resulta gracioso y que mi interlocutor no quiere entablar una conversación sobre jamones ni pedirme uno ${ }^{4}$. Se trata en todos los casos de expresiones a partir de las cuales los hablantes queremos decir algo distinto de lo que expresan sus significados literales, y que, sin embargo, usamos habitualmente con la convicción de que serán entendidas en el sentido adecuado. El lenguaje figurado ${ }^{5}$ conforma un conjunto riquísimo de posibilidades expresivas que, lejos de tener como objetivo prioritario adornar nuestro discurso - aunque, ciertamente, esta pueda ser una de las razones de su uso- tiene sobre todo que ver con la capacidad y con el interés que mostramos continuamente los hablantes por no expresar siempre de manera directa nuestras intenciones. El juego de lo implícito, como explica Ducrot (1982) hunde sus raíces en razones antropológicas y sociales ${ }^{6} \mathrm{y}$, aunque siempre ha sido evidente su presencia en el discurso, has-

4 Wayne Booth (1989: 36-38) no habla de competencia comunicativa, pero presenta una propuesta sobre el proceso que lleva a cabo un lector en la reconstrucción del significado irónico de una novela. Se trata de un intento de racionalizar cuáles son los mecanismos mentales que nos permiten comprender un tipo particular de significado no literal como es el irónico. Los cuatro pasos son: 1) Al lector se le exige que rechace el significado literal. 2) Se ensayan interpretaciones o explicaciones alternativas. 3) Debe tomarse una decisión sobre las creencias propias del autor que está directamente relacionada con la interpretación de la ironía. 4) Una vez tomada una decisión sobre los conocimientos o creencias del hablante, se elige un significado o conjunto de significados de los que podamos estar seguros. Sobre los procedimientos de identificación de la ironía, ver también Hutchens (1960), Muecke (1982) y Mizzau (1984).

5 El propio DRAE, haciéndose eco de la Retórica clásica, se refiere a «cada uno de ciertos modos de hablar que se apartan de los más habituales con fines expresivos o estilísticos». Hay que recordar que el conjunto de recursos del lenguaje figurado que denominamos «figuras» no fue concebido para elaborar un texto poético, sino un discurso retórico cuya finalidad era incidir a través de la palabra en el receptor. Es en esa «retoricidad» natural del lenguaje (López Eire, 1998: 56) en la que encuentran su lugar todos los recursos que hacen posible la expresión de lo implícito.

- La primera razón sería la existencia de tabúes linguísticos y temáticos tanto colectivos como en relación con determinados individuos o situaciones comunicativas. La segunda razón tiene que ver con la necesidad de no realizar afirmaciones explícitas que incitan de inmediato a la confrontación y al enfrentamiento (Ducrot 1982: 1011). Sobre las distintas reacciones de los hablantes ante un acto irónico, resulta muy revelador el trabajo de Helga Kotthoff (2003) pues en él se pone de manifiesto que el hablante no siempre responde a lo implicado en el enunciado irónico sino que, en ciertos contextos, responde sobre todo a lo dicho dando lugar a una broma continuada que estrecha lazos, lima diferencias y de la que todos los interlocutores pueden sentirse cómplices. 
ta el desarrollo de las corrientes pragmáticas a primeros de los sesenta del siglo xx, la Lingüística no tomó como materia propia este aspecto tan fundamental de la comunicación humana. La propia evolución de la disciplina ha llevado a algunos autores a plantear que estos procedimientos y, en particular, la ironía, se consideren como fenómenos metapragmáticos, es decir, relacionados con el uso reflexivo y consciente que los hablantes realizamos del lenguaje. «La metapragmática - afirma Reyes (2002: 23) - es un nivel de análisis dentro de la pragmática, nivel que incluye explícitamente las operaciones que reflejan la conciencia de los hablantes sobre las prácticas lingüísticas». Se trata de una propuesta avanzada - que en el mundo hispánico tiene como principal representante a Graciela Reyes (2002), en la misma línea que Verschueren (2002)— que da un paso más en el camino de entender y explicar por qué los hablantes hacemos determinadas elecciones a la hora de construir nuestro discurso; y, no cabe duda, expresarse de forma irónica es una de las maneras más evidentes de hablar intencionalmente, reflexionar sobre lo que se dice y sus consecuencias y hacerse entender al mismo tiempo. A lo largo de este trabajo tendremos ocasión de volver sobre el tema.

1.2. Los estudios lexicográficos, ante el estímulo que ha supuesto el desarrollo de las corrientes pragmáticas, han considerado también con especial atención la importancia de estos aspectos del significado y han realizado planteamientos teóricos sobre la forma de incluirlos adecuadamente en la descripción lexicográfica, abriendo con ello una reflexión necesaria sobre el aspecto funcional, además de estrictamente lexical que debe ofrecer el diccionario (Haensch y otros, 1982 y Haensch, 1997; Blecua, 1990; Safarti, G.-E., 1995; Garriga Escribano, 1996 y 1997; Albert, 1996; Mateu, 1999; Pérez Lagos, 1999; Azorín Fernández, 2000; Jiménez Hurtado, 2001). En algunos de estos trabajos, se consideran rasgos pragmáticos en la definición lexicográfica la presencia de lo extratextual o extralingüístico como, por ejemplo, la incorporación de palabras actuales -ordenador-o la renovación en las definiciones - marxismo, golpismo - en las que, además, se hacen presentes el lexicógrafo y su mundo (Albert 1996: 19). También la presencia de indicadores dentro de los artículos que evidencien algún tipo de subjetividad tales como deixis temporal, elementos valorativos, sufijos afectivos, elementos egocéntricos, etc. (Mateu 1999: 212-219) que, en realidad, no responden a ninguna intencionalidad pragmática por parte del lexicógrafo sino que se han «colado» en los artículos tal y como muestra su corrección en ediciones posteriores del Diccionario - en este trabajo se compara el DRAE 1984 con la edición en CD-ROM del DRAE 1992-. Aunque estos aspectos son con seguridad consecuencia de las relaciones contextuales que mantienen todos los participantes en el proceso comunicativo, en pocos de estos trabajos se plantean asuntos nucleares como qué es lo que la Lexicografía y, en consecuencia, los diccionarios, pueden obtener de beneficioso de las propuestas de la Pragmática o de qué manera y hasta qué punto los métodos de la Pragmática pueden servir para dilucidar los borrosos límites que los hablantes fijan entre los significados, establecer algún tipo de clasificación y que esta se refleje en el Diccionario. Es evidente, como ya nos advirtió Wittgenstein, en su Tractatus lógico-philosophicus, que el significado de un término sólo encuentra su verdadero sentido inmerso en una situación idiomática. «Solo al ser usado, es decir, inscrito en la estructura proposicional, el nombre ingresa propiamente en los horizontes del lenguaje», y que, llevada a su extremo, esta afirmación lo hace prácticamente inaprehensible. Pero 
no es menos cierto que los hablantes asignamos significados más o menos fijos a las palabras y expresiones de una lengua y que, con idéntica facilidad, las especializamos, como señalábamos en los ejemplos de enunciados irónicos, en expresar un significado distinto.

Así pues, como estamos viendo en este recorrido inicial, Lexicografía y Pragmática, aunque con distintos objetivos y métodos, comparten el amplio espacio de intereses que supone investigar en el significado de las palabras y expresiones de una lengua que hacen posible la comunicación entre sus usuarios y, en consecuencia, su relación es, como indica Pérez Lagos (1999: 121), cada vez más ineludible:

Parece imprescindible, pues, para una Lexicografía acorde con los últimos tiempos, profundizar en el aspecto pragmático y funcional, y que el diccionario ofrezca el uso del lenguaje no como un mero conjunto de observaciones complementarias de su tradicional papel definitorio, sino como la otra cara inseparable de nuestro léxico sin la cual es imposible llegar a un completo conocimiento de nuestra lengua actual.

1.3. Pues bien, es en ese espacio común en el que cobra sentido este trabajo. El grupo de investigación al que pertenezco - GRIALE $^{7}$ - tiene como objetivo actual encontrar un tratamiento lingüístico satisfactorio para el análisis de la ironía verbal en español de manera que, entre otros fines teóricos y prácticos, se pueda aplicar a la enseñanza de español a estudiantes extranjeros. El análisis se aborda desde una perspectiva pragmática y, en este sentido, tiene como referencias ineludibles las teorías al respecto desarrolladas en el seno de esta disciplina ${ }^{8}$. Sin embargo, a la vista de nuestro objetivo último -comprender los mecanismos de la ironía y aplicarlo a la enseñanza de extranjeros-

${ }^{7}$ GRIALE es un grupo de investigación formado por miembros del Área de lengua española del Departamento de Filología española de la Universidad de Alicante. Este grupo es la base de la Unidad Singular de Investigación en Pragmática del español de dicha Universidad y, en la actualidad, le ha sido concedido el Proyecto de Investigación del MEC HUM2004-01318/FILO 2005-2008 titulado «Análisis pragmático de la ironía verbal. Tipología y aplicaciones a la enseñanza del español como lengua extranjera», dirigido por Leonor Ruiz Gurillo. Una presentación de sus objetivos y líneas de trabajo en Ruiz Gurillo, L., Marimón, C., Padilla, X. y Timofeeva, L. (2004).

${ }^{8}$ Los primeros teóricos de la pragmática intentaron formular el concepto clásico de ironía de «decir lo contrario» bajo los principios del análisis pragmático y, en ese sentido, tenemos los trabajos inaugurales al respecto de Grice y Searle. Para Grice (1975), la ironía se explica como la violación de la máxima de cualidad: no diga nada que crea falso, y para Searle (1980), la ironía es un acto de habla indirecto que no cumple el principio de literalidad. Por su parte, Ducrot y Sperber y Wilson parten de un planteamiento distinto y observan el fenómeno de la ironía como un caso de polifonía donde un hablante expresa un enunciado que es eco de otro anterior con la particularidad de que el enunciado ecoizado expresa, por el hecho de haberse emitido en unas determinadas circunstancias, una valoración negativa con respecto a la situación, el hecho o el individuo al que se refiere y eso no necesariamente tiene que ser lo contrario de lo enunciado. Por ejemplo, unos amigos míos, profesores los dos, dijeron la frase: “ ¡Nos ha tocado la lotería!» al contarnos que se había mudado al piso de al lado del suyo una familia con cinco hijos entre cuatro y diecisiete años, un gato y dos periquitos. Según el esquema de Torres Sánchez (1999: 100) a partir de la teoría de Sperber y Wilson, el hablante estaría emitiendo un enunciado en el que se ecoiza una opinión generalizada con la que se compromete -que a alguien le toque la lotería, en principio es algo claramente beneficioso-, pero la información contextual presenta tal enunciado como inadecuado - no parece un gran golpe de fortuna el que alguien dedicado al estudio tenga como vecinos una familia con tantas posibilidades de ser muy nuidosa y molesta-. Un panorama breve y clarificador en Torres Sánchez, 1999, Reyes, Baena y Urios, 2000, Reyes, 2002 y Ruiz Gurillo, 2005. Sobre las dificultades para «medir» la ironía, ver Garzanti, 1988. 
parece importante, además de tener un marco teórico consolidado, tener una idea clara acerca de cómo es tratada la ironía como fenómeno verbal-comunicativo en nuestro idioma y reflexionar sobre ello. Recurrir al $D R A E$ es un punto de partida y una referencia ineludible.

Con este objetivo de fondo, en este trabajo voy a analizar el concepto de «sentido irónico» o de «ironía» que se desprende de su uso en el DRAE de 2001. Partiré del estudio de la transformación de la definición de «ironía» desde la primera edición del $D R A E$ hasta la actualidad, pues creo que los cambios que han tenido lugar en el artículo dicen mucho sobre las dificultades que entrañan tanto la definición de este concepto, como el establecimiento de unos criterios estables para la aplicación de la marca «irón.» a lo largo de la microestructura del Diccionario. La ironía, una manifestación especialmente difícil de explicar del lenguaje figurado, al tiempo que extraordinariamente frecuente en cualquier intercambio comunicativo, tiene su presencia en el DRAE desde la primera edición, tanto como entrada como en su naturaleza de marca. Hace algunos años, Cecilio Garriga (1996) escribió un interesante trabajo sobre la presencia de esta marca en el DRAE. En él nos presentaba la evolución histórica de la marca en los diccionarios académicos hasta la vigésimo primera edición, analizaba los tipos de palabras en los que aparece la marca «irón.», así como las distintas formas de codificación y observó, efectivamente, los problemas en cuanto a la coherencia, la codificación y el lastre tradicional que arrastraba el uso de esta marca en el Diccionario de 1992. En opinión de Garriga, es, precisamente, la necesidad de inmediatez $\mathrm{o}$, al menos, de amplios márgenes de conocimiento compartido entre los hablantes que participan en un intercambio irónico lo que, sin duda, dificulta, limita y condiciona la aplicación de la marca «irónico» en los Diccionario, y, en este sentido, afirma: «Debido a que la ironía adquiere su sentido en una situación comunicativa concreta, es difícil que una expresión se pueda considerar irónica sino está contextualmente definida» (Garriga 1996: 108). Este problema9 ${ }^{9}$ que ya anunciábamos anteriormente, afecta no sólo a la ironía sino, en realidad a cualquier marca pragmática; en esa misma línea afirma Jiménez Hurtado (2001: 388-389) que, puesto que cualquier palabra puede tener intención «sólo llevarán la marca las que tengan un valor pragmático refrendado y aceptado por la comunidad que se trate.» Ya centrada en el caso de las expresiones fijas irónicas y su tratamiento en el Diccionario, también Inmaculada Penadés (1999: 197) recomienda «limitar la marca irónico en los diccionarios a aquellas expresiones fijas que en todos los contextos lo son.» Pero ni siquiera es tarea fácil seleccionar cuáles son esas expresiones que los hablantes consideramos irónicas pues para ello sería necesaria una teoría capaz de dar una respuesta clara a qué es una ironía y, en mi opinión, todavía no la hay.

Puesto que el objetivo es estudiar el tratamiento de la marca irónico en el DRAE y extraer de ello la teoría o los principios teóricos que puedan resultar más útiles y esclarecedores, he organizado la tarea de la siguiente forma. En primer lugar trataré de la de-

${ }^{9}$ Una investigación bastante reciente en este sentido es la que ha llevado a cabo Akira Utsumi (2000) según el cual, la interpretación de una ironía depende en gran medida de la existencia de lo que denomina un entorno irónico -ironic environment - que, según Utsumi (2000: 1783-1784), contiene las siguientes condiciones - events o states-: las expectativas del hablante en un espacio y un tiempo concretos, la incongruencia entre las expectativas y la realidad y, finalmente, una actitud negativa del hablante hacia la incongruencia entre lo que se esperaba y lo que ocurre realmente. 
finición que proporciona el DRAE 2001 del concepto ironía y observaré los posibles cambios que hayan podido tener lugar históricamente (apartado 2). En segundo lugar voy a intentar establecer qué clase de criterio se ha utilizado para señalar una palabra o una expresión como irónica, si se ha aplicado al adjudicar la marca la definición que ofrece del término el propio Diccionario o si se ha optado por otros criterios (apartado 3). Además, en este mismo apartado, estudiaré las diferencias que se pueden señalar entre la adjudicación de la marca «irón.» propiamente dicha o de las correspondientes notas de uso. Pero en cualquiera de los dos casos, me interesa saber si es posible reconocer el sentido irónico de una palabra o una expresión a partir de la información que nos ofrece el Diccionario y qué consecuencias podemos sacar de ello. A lo largo del trabajo se hará referencia a las teorías pragmáticas sobre la ironía que podrían reforzar o cuestionar las decisiones tomadas en el DRAE 2001. No es pues la perspectiva del Lexicógrafo, que no lo soy, la que adopto, sino más bien la del Lingüista interesado en la pragmática que quiere clarificar y estudiar el fenómeno comunicativo de la ironía verbal en español y que recurre al DRAE como primera y privilegiada fuente de información. Tanto el $C R E A^{10}$ como los corpus COVJA ${ }^{11}$ y $A L C O R E^{12}$ nos servirá para ejemplificar contextualizadamente el verdadero uso irónico de muchas de las expresiones que llevan esa marca en el DRAE 2001 así como constatar en otras ocasiones la actualidad de dichas marcas.

\section{El CONCEPTO DE IRONÍA EN EL DRAE: LA DEFINICIÓN}

2.1. En la vigésimo segunda edición del $D R A E$ la entrada «ironía» presenta tres acepciones:

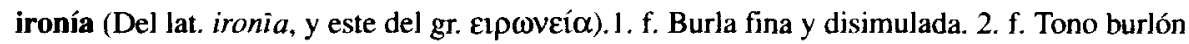
con que se dice. 3. f. Figura retórica que consiste en dar a entender lo contrario de lo que se dice.

Sin embargo, no siempre han sido estas, como vamos a comprobar, ni las acepciones de la entrada, ni el orden de su aparición. En la primera edición del Diccionario - 1780 - la Academia recoge sin variación la definición fijada en el Diccionario de Autoridades, tomo IV, que se publicó en 1734. El artículo de 1780 queda como sigue:

IRONÍA. s. f. Ret. Figura con la que se quiere dar á entender, que se siente, ó se cree lo contrario de lo que se dice. Y la explica el énfasis del tono, ó acción con que se habla. Ironía, illusio.

${ }^{10}$ Me refiero al Corpus de Referencia del Español Actual que se puede consultar en la página web de la Real Academia Española (www.rae.es)

"El Proyecto COVJA (CORPUS ORAL DE LA VARIEDAD JUVENIL UNIVERSITARIA DEL ESPAÑOL HABLADO EN ALICANTE), dirigido por Dolores Azorín Fernández y Juan Luis Jiménez Ruiz (1999) fue posible gracias a la subvención del Instituto Alicantino de Cultura Juan Gil-Albert de la Excma. Diputación Provincial de Alicante. En lo sucesivo se citará en el texto como COVJA.

12 El proyecto ALCORE (ALICANTE-CORPUS ORAL DE ESPAÑOL), dirigido por Dolores Azorín Fernández (2002) fue posible gracias al Proyecto de Investigación I+D del Ministerio de Educación y Cultura PB98-0967 y a los contratos de investigación suscritos con el Instituto Alicantino de Cultura Juan Gil-Albert, de la Excma. Diputación Provincial de Alicante. A parir de ahora los textos procedentes de dicho corpus se señalarán como $A L C O R E$. 
Se trata, tal y como indica la marca Ret., de una definición directamente emparentada con las teorías al respecto que elaboró la Retórica clásica. Aunque en la definición del Diccionario se habla de «figura», la tradición retórica considera, en general, la ironía, tanto un tropo, es decir, un recurso que se puede llevar a cabo únicamente con algún tipo de modificación en una palabra, como una figura, es decir, una modificación más compleja que afecta a un segmento mayor del discurso. Como tropo, la ironía es un cambio en la significación, una dislocación en el significado que afecta a un único término; en este sentido, la ironía es definida como la expresión de una cosa mediante una palabra que significa lo contrario de ésta: "Rechazado por él, te pusiste a vivir con tu compañero, hombre nobilísimo, Metello» (Cat., 1,8,19). En dos palabras precisamente -optimo, Metello- está la ironía, por consiguiente es también más breve el tropo» ${ }^{13}$ (Quint., IX, $2,45)$. Es un tropo de palabra pero que, sin embargo, tiende de forma natural hacia la figura o tropo de pensamiento.

Como figura, la ironía se considera, a su vez, también tanto una figura de pensamiento como una figura de dicción, pero al igual que la metáfora, con la que comparte la pertenencia a ambas categorías, la ironía tiende a figura de pensamiento, pues «la ironía expresada en una palabra colorea toda la expresión o contexto con un matiz irónico» (Lausberg, 1980: II, 582-585). Así lo considera también el propio Quintiliano en sus Instituciones oratorias:

En la figura de la ironía se trata del fingimiento de toda la intención, que se trasluce más que se manifiesta, de suerte que allí - en el tropo- las palabras son contrarias unas a otras, mientras aquí —en la ironía como figura- - se contrapone el sentido a la expresión completa y a su tono, y a veces al configuración entera de un caso, hasta una vida entera, puede tener ironía. [...] de suerte que lo mismo que una metáfora continuada forma alegoría, así forma el tropo de la ironía con todo su contexto esta correspondiente figura (Quint., IX. 2, 46)

Así entendida, la ironía se explica como una alegoría en la que lo «al-lo» no es un objeto comparativo mentado en serio, sino lo contrario como explica también Quintiliano en otro lugar de la misma obra:

Pero al género de alegoría en la que se muestran cosas contrarias, pertenece la ironía. Los romanos la llaman inlusio (mofa). Se la reconoce, o por el modo de decir o tono, o por la persona o por la naturaleza de la cosa; pues si alguna de estas cosas contradice a lo que suenan las palabras, es claro que lo que quiere decirse es distinto a lo que realmente se ha dicho. Aunque en la mayoría de los tropos ocurre que la diferencia consiste en lo que se dice respecto a cada cosa, porque es realmente verdad lo que se afirma en otro lugar. En el uso de la ironía está permitido desacreditar a uno fingiendo una alabanza y alabarlo bajo la apariencia de un reproche (Quint., VIII, 6, 54-55).

A lo largo de la tradición retórica posterior y, por lo que a nosotros nos interesa, en la tradición retórica española del $\mathrm{s}$. XVI, se ofrecen definiciones en las que se hace énfasis en la discordancia que se produce entre lo dicho y el tono o el movimiento corporal con el

13 Todas Jas citas de Quintiliano se refieren a su obra Institutionis oratoriae que he manejado en la edición bilingüe de 1997 reseñada en la bibliografía. 
que se acompaña ${ }^{14}$. Para Sempere la ironía es el «Tropo por el que en el gesto del cuerpo o la pronunciación mostramos que queremos decir otra cosa distinta de la que decimos para burlarnos [... ]». Para Palmireno es la significación de algo por su opuesto, e incluye entre las señales para su reconocimiento la propia naturaleza de lo que se dice» (Luján Atienza 1999: 164). Lo mismo que Miguel de Salinas en su Retórica de la lengua castellana de 1541 (Casas 1980: 185-186), cuya explicación de la ironía coincide tanto con las anteriores, como con la Académica aunque con una observación final sobre las intenciones de la que hablaremos más adelante:

Ironía es cuando decimos lo que queremos por palabras que significan lo contrario y ayudámoslo con el gesto y pronunciación; y hácese por hacer burla, o por reprender, o por contradecir.

En la actualidad, los manuales y libros sobre recursos literarios siguen sin situar definitivamente a la ironía entre los tropos o entre las figuras de pensamiento, pero las definiciones hacen toda clara referencia al concepto de «lo contrario», como vemos en las dos siguientes citas:

Ironía. Figura de supresión-adición. Consiste en presentar una expresión cuyo significado es contrario al que realmente tiene, si bien a partir del cotexto e incluso del contexto el receptor puede reconstruir el significante que el productor desea que se entienda (Albaladejo 1989: 147).

La ironía es la expresión de un pensamiento a través de un enunciado de sentido literal diferente o incluso opuesto a lo que en el fondo se piensa y se pretende decir; de manera tácita, el contexto presenta las claves necesarias para la interpretación de este discurso simulatorio (Azauste-Casas 1997: 89-90).

2.2. Perfectamente asentado en la tradición, el artículo permanece inalterable a lo largo de catorce ediciones del Diccionario hasta que en la decimoquinta, de 1925, encontramos varios cambios sustanciales:

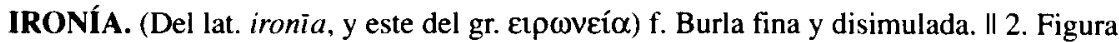
retórica que consiste en dar a entender lo contrario de lo que se dice.

Lo primero que llama la atención es que de la definición procedente de la tradición retórica se ha eliminado la parte que hace referencia a la importancia del tono o la acción para evidenciar el sentido irónico. Este recorte parece un intento por concentrar en aspectos estrictamente linguísticos y verbalmente reconocibles la determinación de lo que es irónico, buscando una dirección más rigurosa e inmanentista en las definiciones acorde, quizá, con el giro que, por aquellos años, los estudios lingüísticos y literarios estaban dando en España. Pero, además, esa acepción, que ahora ya no lleva la marca Ret. sino que se

14 Sobre la trayectoria histórica del concepto de ironía y los distintos intentos de definición hay una abundante bibliografía. Además del trabajo de Knox (1961), ver también D. Knox (1989): Ironia. Medieval and Renaissance Ideas about Irony, La Haya, Brill; H. Morier (1981): Dictionaire de Poétique et de Rhétorique. Paris, Presses Universitaires de France y Ph. E. Wiener (ed.) (1973): Dictionary of the History of Ideas, N. Cork, Charles Scribner's Sons. 
define directamente como «figura retórica», tal y como, por otra parte, aparecía en el Diccionario de Autoridades, tomo IV, de 1734, ya no es la única, porque se le antepone otra: «Burla fina y disimulada». Y este es el segundo cambio. El concepto de burla aparecía, como hemos vimos, en las definiciones del XVI pues, en definitiva, desde las primeras formulaciones del concepto de ironía se considera que burlarse del otro -ponerlo en ridículo- es uno de los objetivos de su uso. De hecho, tanto la dissimulatio como la simulatio -que constituyen los dos grados y las dos formas de ironía que reconoce Quintiliano (VI, 3,85 )- eran formas de ridiculizar al contrario dándole aparentemente la razón; en las clasificaciones griegas, la «ironía de personas extrañas» consistía en la burla y el escarnio (Lausberg, 1980, III, 120) y no olvidemos que la ironía socrática no tenía otro objetivo que poner en evidencia al otro mostrando su ignorancia. Con esta nueva acepción, pues, el rígido concepto de «lo contrario» da lugar a una concepción más amplia de la ironía y de las posibilidades del juego irónico, haciendo explícita su intencionalidad y emparentándola así con la fecunda y problemática familia del «humor». Desconozco la razón por la que se toma la decisión, pero al revisar las palabras y expresiones que el propio Diccionario reconocía como irónicas, se pone de manifiesto que, en la práctica, el concepto de burla estaba presente a la hora de adjudicar la marca. Es el caso, por ejemplo, de «bienaventurado", presente en el Diccionario con la marca irónico desde la primera edición y que la conserva aún hoy. En su tercera acepción en la edición de 2001 se lee:

3. adj. irón. Dicho de una persona: Demasiado sencilla o cándida. U.t.c.s.

Al buscar alguna ocurrencia en el CREA, en ninguno de los casos se explica el sentido irónico según el concepto de "sentido contrario", sino más bien el de ridiculización o distanciamiento como en el siguiente ejemplo procedente de la novela de José Antonio Gabriel y Galán, El bobo ilustrado:

Sentiste un primer escalofrío al contacto de sus manos, del agua fresca, ¿a qué negarlo? Ese estremecimiento se fue paseando por tu cuerpo sin detenerse en parte alguna, diluyéndose posteriormente en un deleite sosegado y general. El bochornoso agobio nocturno desapareció, el vinillo seguía cayendo a gusto en la madriguera y habrías de confesar que parecías un bienaventurado.

2.3. El tercer y último cambio en el artículo referido a la ironía hasta la edición de 2001 se produjo en la vigésima edición, de 1984. Como señalábamos anteriormente, en la edición de 1925 se había recortado la definición procedente de la retórica eliminando la parte final referida al tono, "y la explica el énfasis del tono o acción con que se habla». En 1984 se recupera la alusión a este aspecto en una nueva segunda acepción que relega la definición retórica al tercer lugar:

ironía. f. Burla fina y disimulada. || 2. Tono burlón con que se dice. II 3. Figura retórica que consiste en dar a entender lo contrario de lo que se dice.

Al introducir esta acepción, el Diccionario hace recaer la decisión acerca de la naturaleza irónica de un enunciado también sobre «elementos no conceptuales» (Casares 1969: 105) directamente relacionados con la intención o el estado del ánimo de quien ha- 
bla o con el propio asunto que se trata, según reza en la definición de tono que ofrece el propio Diccionario. Precisamente sobre los límites en la introducción de los valores afectivos $\mathrm{y}$, concretamente, en relación con la ironía, se había pronunciado en sentido contrario a esta decisión Julio Casares (1969: 114) en el apartado referido a la ironía y la comicidad de su Introducción a la Lexicografía moderna:

El efecto que ha de tenerse en cuenta es el que procede del hecho expresivo considerado en sí mismo y no de otros factores concomitantes. Los antecedentes, el contexto, o el simple énfasis en la pronunciación bastan en muchos casos para comunicar sentido irónico al vocablo más inocente

Y pone el ejemplo de «elegante» y «espléndido», adjetivos que, según cómo y en qué situación se digan, pueden indicar eso mismo o todo lo contrario. Al introducir, pues, la alusión al tono, se abre la posibilidad de considerar irónico casi cualquier enunciado, lo cual, si bien da a la ironía su verdadera naturaleza de discurso contextual, dificulta enormemente la posibilidad de delimitar qué es o qué no es irónico y pone a la Academia en la disyuntiva de tener que establecer la pertinencia del tono como criterio para marcar o no una acepción como irónica o bien para decidir el uso irónico de una expresión, como veremos más adelante.

2.4. Así, finalmente, nos encontramos en la actualidad con una triple definición de ironía en la que entran en juego, en primer lugar, la intencionalidad con la que se realiza la ironía - burlarse, poner en ridículo a alguien-, en segundo lugar, la forma de expresar y reconocer el sentido irónico, es decir, el tono que invita a entender el sentido ridiculizante de lo dicho y, finalmente, el procedimiento verbal con el que se consigue: expresar con palabras lo contrario de lo que se quiere decir. En cuanto al orden, puesto que se trata de tres acepciones de la misma categoría gramatical y sin ninguna marca, es de esperar que el criterio adoptado sea el que propone el propio Diccionario en sus «Advertencias para el uso (5.3.2.)»: «se tiende a anteponer las acepciones de uso más frecuente y posponer las de empleo más esporádico». Debemos suponer, pues, que la intención burlesca se considera la forma más reconocible y extendida de expresión de la ironía, que, a continuación, es el tono lo que hace que un enunciado sea o no irónico y sólo en último lugar se considera como irónico expresar de forma indirecta o no literal el sentido de un determinado enunciado. Pero lo que no quedan claras son las relaciones entre las tres acepciones, es decir, si para que un enunciado sea irónico tienen que confluir una intención burlesca o ridiculizante con una inversión semántica o si sólo la presencia de la inversión o la intención de burla - unido o no en ambos casos a un determinado tono- nos permiten identificar un enunciado como irónico. Creo que el análisis de la distribución de la marca irónico en el DRAE 2001 nos ayudará a sacar alguna conclusión.

\section{LAS IRONÍAS DEL DRAE}

En el DRAE 2001 hay 153 marcas «irón./irons.» distribuidas en 137 entradas. Además, las palabras «irónico», «irónica», «irónicamente», «ironía», aparecen en 27 oca- 
siones en el interior del artículo aunque hay, al menos, 10 ocurrencias de tipo metalinguístico. De las 153 marcas, 42 corresponden a notas de uso - un 27,4\%-y el resto -111, un 72,6\%-, a la marca propiamente dicha situada al principio de la acepción. La Nueva Planta del Diccionario ha eliminado combinaciones con otras marcas, como ocurría anteriormente, excepto en dos ocasiones, «rico», en la que aparece la nota de uso «U. t. en sent. irón. o despect.» $y$ «speech» que se marca como «despect. e irón.». Las notas de uso se limitan a «U. t. en sent. irón.» y «U. m. en sent. irón.».

Para analizar el concepto de ironía que se desprende del uso de la marca que se realiza en el Diccionario vamos a distinguir el tratamiento de las notas de uso del tratamiento de la marca como indicadora de la intención del hablante. Empezaremos por el análisis de esta última.

\subsection{La marca «irón.»}

3.1.1. Al estudiar las ocurrencias de la marca hemos podido comprobar que en aproximadamente 61 ocasiones la marca «ironía» se corresponde con palabras, frases o expresiones cuyo sentido irónico debe entenderse como el sentido contrario. En todos estos casos, es el propio Diccionario el que induce - si no indica directamente- dicha interpretación, como ocurre, por ejemplo, con «alhaja», «boca de verdades», «tener algo chiste», «dama», «decentemente», «friolera», «gracia», «gracioso» «lindeza», «música», «nene» «buena pieza», «ir alguien servido» o «vahear», entre otras. El sentido contrario procede, en algunas ocasiones, del hecho de que la marca «irón.» aparezca en una de las acepciones de la palabra, de manera que el hablante tiene la referencia del significado denotativo y entiende el significado irónico como, efectivamente, lo contrario del significado anterior. Es el caso claro de «boca de verdades» que tiene como primera acepción «persona que dice a otra con claridad lo que sabe o siente» y como segunda, irónica, «persona que miente mucho». Muy parecidos son los casos de «friolera», «gracioso», «lindeza», «música», que se definen en su acepción irónica con un significado claramente contrario al denotativo. En las entradas que siguen he señalado en negrita la acepción denotativa y la irónica para que se observe mejor el contraste entre ambas:

friolero, ra. (De frior y -ero, con disimilación de r). 1. adj. Muy sensible al frío. 2. f. Cosa de poca monta o de poca importancia. U. m. c. antífrasis. 3. f. irón. Gran cantidad de algo, especialmente de dinero.

gracioso, sa. (Del lat. gratiōsus). 1. adj. Que resulta agradable o atractivo a la vista. 2. adj. Chistoso, agudo, lleno de donaire. Apl. a pers., u. t. c. s. 3. adj. Que se da gratuitamente. 4. adj. irón. coloq. Molesto, sin gracia. Apl. a pers., u. t. c. s.

lindeza. 1. f. Cualidad de lindo. 2. f. Hecho o dicho gracioso. 3. f. pl. irón. Insultos o improperios.

música. (Del lat. musǐca, y este del gr. $\mu \sigma v \sigma i k n ́)$. 8. f. Sonido grato al oído. La música del viento entre las ramas. La música del agua del arroyo. 9. f. irón. Ruido desagradable. 
En el siguiente ejemplo del corpus ALCORE un hablante utiliza la expresión «ivaya gracia!» precisamente para mostrar lo poco agradable de la situación:

$\langle T l, M, 3, S u, E E, E\rangle$ : Mi prima fue allí, hace $<$ palabra cortada $>$ po $<$ palabra cortada $><$ vacilación $></$ vacilación $>$ la semana pasada, dejó el coche y cuando fue toda una parte $<$ pausa $><$ pausa $>$, no puede entrar por la puerta. Y no, como no hay cámaras ni nada no saben quien ha sido. $<$ número $>$ Ciento y pico mil $<$ /número $>$ pesetas. Recién arregla $<(d)>0$ el coche.

\section{$<T 3, H, I, B a, E E, V>$ : Pues vaya una gra $<(c)>i a$.}

En otro grupo de entradas marcadas con «irón», el sentido contrario es producto de una lexicalización o especialización, sobre todo de expresiones, locuciones y frases, en comunicar lo contrario de su significado literal. En la mayoría de las ocasiones, la expresión de lo contrario queda acentuada por el hecho de aparecer en dichas expresiones adjetivos valorativos polares marcados positivamente que, sin embargo, se van a usar en sentido contrario. Es el caso de «bueno anda el ajo», «estar o ir arreglado, apañado o aviado», «estaría bueno que», «lo bueno es que», «buena es esa», «cualquier día», «el mejor día», «buena finca», «cubrirse alguien de gloria», «ahí es un grano de anís», «haberla hecho buena», «buena hacienda», «buena hipoteca», «alabo la llaneza», «colgar a alguien el milagro», «buena, gentil, linda pieza», «todo en gordo», $\mathbf{0}$ «variaciones sobre el mismo tema». La definición que ofrece el Diccionario en estos casos pone en evidencia ese sentido irónico de contradicción y así «el mejor día» se utiliza para expresar el temor a un contratiempo, «todo en gordo» para expresar la escasez o pequeñez de una dádiva o cosa y se «alaba la llaneza» para, en realidad, reprender a quien la ha usado indebidamente.

En todos los casos que hemos visto hasta ahora, el efecto irónico puede explicarse a partir del contraste que se produce entre un enunciado que emite un juicio positivo sobre un hecho, acción o persona, pero que choca contextualmente con una realidad inadecuada (Shoentjes 2003: 122). Desde esta perspectiva, el idioma parece haber especializado un conjunto de expresiones y acepciones en realizar esta función; son palabras cuyo objetivo es «usar mal» deliberadamente el lenguaje, como explica Graciela Reyes (2000: 20), palabras que dan lugar a enunciados falsos que suponen una violación de la máxima de cualidad de Grice y que, en consecuencia, conducen al destinatario a tener que extraer implicaturas para explicarse y justificar el significado del hablante. Pueden entenderse también estas palabras y expresiones, como proponen Sperber y Wilson, como ecos de enunciados anteriores que evocan verbalmente una situación en la que sus significados literales tenían sentido en relación con una determinada situación ${ }^{15}$ pero que, en el momento actual de la enunciación, ya no lo tienen. El problema es que, en muchos de estos casos, como hemos visto, el proceso de fijación formal y semántica —en particular de las expresiones fijas irónicas - es tan fuerte que, probablemente, el destinatario no procesa ya el impacto entre realidad negativa y expresión positiva en el que se resuelve un enunciado irónico, sino que recibe directamente la expresión como una manifestación de dis-

\footnotetext{
15 Remito a las referencias de la nota cinco de este trabajo para la explicación de estas teorías.
} 
gusto o desacuerdo con lo dicho o lo hecho, como ocurre en el siguiente ejemplo de la novela de Lola Beccaria, La luna de Jorge:

[...] pues adelante. Aclárame lo que ha de acontecernos, pobres desgraciados de nosotros.

-Pues que tú te cansarás de mí en un par de meses y yo acabaré hecho un guiñapo tristísimo, tirado en la cuneta.

Con maldiciones como esa estamos apañados. Ya has sentenciado lo nuestro, y quieres destruirlo, no hay duda.

«Apañado», significa adecuado a una determinada situación, pero la expresión «estar apañado» significa precisamente encontrarse en una situación incómoda o complicada y, en la actualidad, es, con toda seguridad, si no el único significado, sí el significado preferente que procesan los hablantes. Creo que en ese mismo caso estarían «haberla hecho buena», «cubrirse de gloria», «colgarle a alguien el milagro» o «lucir el pelo», entre otras. Gonzalo Díaz Mingoyo (1980) en un artículo sobre el funcionamiento de la ironía, propone como los tres requisitos irónicos «que su tenor literal sea semánticamente verosímil, pragmáticamente contradictorio y deseable en el contexto de enunciación» (Díaz Mingoyo 1980: 59); pues bien, si para que algo sea considerado irónico es imprescindible que se perciba la contradicción entre el enunciado y la realidad, la mentira que no lo es o el eco de una situación anterior, es evidente que no todas las palabras y expresiones que hemos visto en este apartado realizan esta función con la misma intensidad, es más, en muchas de ellas ese contraste queda minimizado y, en consecuencia, también debe quedar reducida la fuerza o la intensidad del efecto irónico. Desde este punto de vista podemos establecer dos grupos de palabras y expresiones marcadas como irónicas en relación con la fuerza del sentido irónico que trasmiten a los enunciados en los que se insertan: por una parte estarían las que indican «sentido contrario» y que, en el artículo, presentan una acepción que muestra su significado literal y otra en la que se señala el irónico. Este grupo estaría constituido mayoritariamente por palabras y por las expresiones fijas irónicas «boca de verdades», «ya verán quién es calleja» y «tener gracia alguien o algo»; en ellas se cumplirían las condiciones que hacen posible el sentido irónico. Por otra parte, y en un segundo grupo, estaría el resto de expresiones fijas que indican "sentido contrario" pero que presentan una única acepción, la irónica, lo que pone en evidencia el altísimo nivel de idiomaticidad de dichas expresiones $^{16}$, su especialización en expresar lo contrario de lo que dicen y, en consecuencia, una cierta atenuación del sentido irónico al haberse perdido casi completamente el efecto de contraste en el que se resuelven los enunciados irónicos. No debemos olvidar, sin embargo, que todas las palabras y expresiones señaladas hasta ahora tienen en común el constituir una antífrasis o inversión semántica y que este procedimiento es, precisamente, el que ha caracterizado y servido de base para la producción de sentido irónico.

3.2.2. Sin embargo, no es esta la única interpretación de la ironía que nos ofrece el $D R A E$. Hay otro grupo de palabras y expresiones marcadas como irónicas cuyo significado no es el contrario del denotativo. Entre ellas se encuentran: «asuntejo», «asuntillo»,

16 Ver a este respecto los trabajos de Inmaculada Penadés Martínez sobre el tratamiento lexicográfico de las expresiones fijas irónicas, Penadés, 1999 y 2000 . Muy reciente y aún en prensa el trabajo de Timofeeva, L. (2005): «La ironía en las unidades fraseológicas», Interlingüística. 16 (en prensa). 
«bienaventurado», «dolorosa», «dictablanda», «entacuchar», «extrafino», «un jamón con chorreras», «leído y escribido», «mandamás», «tumtumpote», «magíster dixit», «Padre de la Patria», «cuernos», «predestiando», «república», «speech», «turrón», «vidorria», entre otras. Se utilizan para ridiculizar o mencionar burlescamente aquello a lo que se refieren y así, por ejemplo, un speech es un discurso, pero ridículo, como ocurre en el siguiente ejemplo del diario El País de 15 de setiembre de 1977 donde el redactor usa el término para referirse de forma poco positiva a la intervención pública de alguien.

La Bolsa debe convertirse en eje central del sistema financiero, cauce para que el ahorro popular financie las inversiones del mayor número de empresas.m Así, sin más, el vicepresidente para Asuntos Económicos suelta su speech y deja a los interesados en el mercado de valores donde estaban, porque no aporta la más mínima novedad [...].

En este último caso, el tono depreciativo y burlesco se ve, además, acentuado al utilizar el verbo «soltar» para referirse al acto de emitir el Vicepresidente sus palabras. Y «mandamás» es una forma burlesca o no demasiado respetuosa de llamar a quien tiene el poder como hace el periodista del diario El Mercurio:

David Bradley, el inventor de la clásica fórmula de apretar «Ctri+Alt+Supr» para reiniciar el computador, se retira de las pistas informáticas, después de 28 años trabajando en IBM. [...]

Una vez dijo frente al mandamás de Microsoft: «Tal vez yo la inventé, pero Bill la hizo famosa». Gates no se rió.

Son unas 30 palabras y expresiones que tienen sin duda efectos afectivos y que añaden una indudable carga de modalización a los enunciados en los que se insertan, pues constituyen una selección léxica intencional por parte de un sujeto que, al hacerlo, imprime un notable suplemento de significación y abre a su destinatario las puertas hacia una abanico interpretativo mucho más amplio que el que, —en el caso de los ejemplos anteriores - jefe, o discurso, habrían proporcionado. Para entender y justificar que esa carga modalizadora pueda constituir una ironía —como así lo señala el $D R A E$ — puede resultar clarificador recurrir al concepto de metapragmática del que hablábamos al principio de este trabajo. Desde este punto de vista, dichos enunciados se podrían considerar irónicos en la medida en que suponen un proceso de evaluación por parte del hablante que, para conseguir un efecto burlesco y distanciarse de su propio enunciado, elige una palabra o expresión que necesita para su comprensión que el destinatario realice un mayor esfuerzo inferencial del que requeriría el uso de los términos estrictamente apropiados. Aquí la ironía ya no es decir lo contrario, ya no hay contraste ni realidad deseable; aquí la ironía, en efecto, dice otra cosa distinta de su significado literal pero ese significado no es una mentira ni una contradicción; en estos casos, la ironía, dice Graciela Reyes (2002: 87-88) «juega con el uso (corriente, característico, esperable) de las expresiones lingüísticas y, además, sirve para comunicar actitudes, evaluaciones, sentimientos [...]». De entre este grupo de palabras, también las hay que tienen una única acepción irónica, como «dictablanda», «entacuchar» o «speech», o que tienen varias acepciones, una de las cuáles es irónica, como ocurre con «extrafino», «república», «mandamás» o «Padre de la Patria». 
Estamos, pues, en un terreno verdaderamente inestable tanto para la Pragmática como para la Lexicografía y, en consecuencia, no es de extrañar que el $D R A E$ también muestre mayor confusión y arbitrariedad en la adjudicación de la marca en estos casos. Por ejemplo, «meter la gamba» y «percances del oficio» están marcadas como irónico pero remiten para su significado, respectivamente, a «meter la pata» y «gajes del oficio», que, sin embargo, no la tienen. Por otra parte, «valija», entendido como el trasero voluminoso de una mujer, «toronja», como nariz grande y deforme, y «jijas», persona endeble son metáforas depreciativas, sarcásticas, que se pueden usar desde luego con intención irónica, tal y como señala el Diccionario, pero de la misma manera que al llamar «pandero» al trasero voluminoso de una señora, «tarro» a la cabeza o «hueso» a una persona dura y que, sin embargo, en el Diccionario no presentan la marca «irónico» sino la de «coloquial».

Hemos observado que muchas de estas palabras tienen en común el aportar un significado hiperbólico en relación con el concepto al que se refieren, como ocurre, por ejemplo, en el siguiente texto de Jenny E. Hayen, en el que el uso de «entacuchado» para expresar la excesiva elegancia en el vestir de ciertos personajes es, precisamente, la palabra que sirve para disparar las especulaciones tanto del narrador como de los lectores sobre la naturaleza y las intenciones de dichos individuos:

Tirso, el administrador, en suéter cuello de tortuga y chamarra borrega, está parado en lo alto del zaguán, sin bajar todavía los escalones de la entrada. No es extraño que se presente tan temprano y sin que sea día primero porque los taimados —que son también los más morososse esconden obligándolo a venir varias veces al mes, entre semana y hasta un domingo con tal de pescarlos y poder cobrar las rentas, aunque sea en abonos. Sólo que en esta ocasión lo acompañan dos señores entacuchados. Su presencia sobrecoge a todos, parecen cuervos o enterradores. Y el olfato les advierte que, sean lo que sean, no puede tratarse sino de avechuchos de mal agüero. (Hayen, Jenny E. Por la calle de los anhelos, México. 1993)

Junto con «entacuchado» estarían «extrafino» —que lleva, además, un prefijo de intensificación-, «dolorosa», «leído y escribido» o las metáforas depreciativas e hiperbólicas, nombradas anteriormente, «valija» y «toronja». Sin embargo, no siempre lo hiperbólico tiene una connotación negativa. El Diccionario marca como «irón.» otro grupo de palabras, que, a pesar de constituir una selección léxica intencional, no suponen burla ni encierran ningún sarcasmo sino que más bien son hipérboles que se usan para ponderar el elemento al que se aplican. Es el caso de «Califa», referido a los toreros cordobeses y de "canon", entendido como norma propia de una actividad, tal y como vemos en un mismo ejemplo del $C R E A$ y en los que no se aprecia ninguna intención irónica:

Su empaque de obelisco inoculó ansias de vivir a una España destrozada y rota, que volvió a reventar las plazas para ver a este Monstruo llamado a ser Califa III del toreo, cuya concepción de la faena de muleta llevaría al verbo «ligar» a colocarse, junto al trío de infinitivos toreros — parar, templar y mandar-, en el cuarto sillón canónico de Fiesta (Ortiz Trixac, Santi, Lances que cambiaron la Fiesta, 2001).

Es evidente, como decíamos, que estamos en un terreno mucho más indeterminado que aquel que centraba los límites de la ironía en la antífrasis pero. como vamos a com- 
probar de inmediato, la dificultad para precisar el sentido de la ironía resulta aún más evidente en las notas de uso.

\subsection{Las notas de uso}

Los dos tipos de notas de uso relacionadas con la ironía son «U. t. en sent. irón.» y «U. m. en sent. irón.». Aparecen en 42 ocasiones, pero sólo en dos entradas, «entendederas» y "ganga» se explica cuál es el sentido irónico, que, en ambos casos, consiste en expresar lo contrario de lo que se dice en la acepción en la que se incluyen:

entendederas 1. f. pl. coloq. entendimiento. U. m. en sent. irón., denotando la escasez o torpeza de dicha facultad.

ganga' 2 . f. Cosa apreciable que se adquiere a poca costa o con poco trabajo. U. m. en sent. irón. para designar algo despreciable, molesto.

Las cuarenta notas de uso restante no presentan ninguna explicación en relación con la forma de interpretar el sentido irónico, con lo que el usuario tiene que decidirse por adjudicar a las palabras y expresiones correspondientes o bien un sentido burlesco y de evaluación como hemos visto últimamente o, como en las entradas anteriores, de inversión semántica. Una forma de orientar al hablante al respecto es la introducción de ejemplos aclaratorios; sin embargo, en el DRAE 2001 sólo hay ejemplos para las entradas «alhajita», «donoso», «llegar lejos», "pata negra» y «valiente»: «rostro alhajita», «donosa ocurrencia, pregunta, humorada», "cardenal, catedrático de pata negra», «valiente amigo tienes» y «esta chica llegará lejos» respectivamente, que, por otra parte, pueden interpretarse tanto con sentido irónico como en su uso denotativo por lo que su valor aclaratorio, tal y como aparecen en la actualidad, es prácticamente nulo. Así, por ejemplo, si una colega le dice a otra al hablar de una alumna de doctorado que ha realizado unos trabajos excelentes, «está chica llegará lejos», se entiende sin ambigüedad que le está augurando un brillante porvenir académico; pero si esa misma expresión la utiliza para hablar de una alumna que, por tercera, vez realiza un examen desastroso, debe entenderse que la hablante está ironizando y lo que espera que se entienda es que esa persona, literalmente, «no llegará muy lejos» en su trayectoria académica. En todos estos casos, pues, que el hablante se decida por entender la acepción denotativa o la acepción irónica va a depender, exclusivamente, del momento de la enunciación, en el que contexto e intenciones del hablante, conocimiento compartido, experiencial y enciclopédico y competencia comunicativa de ambos converjan para dotarlo de sentido. Es ahora cuando puede entrar en juego el «tono burlón con que se dice» de la definición lexicográfica que funcionaría como una pista o señal no verbal proporcionada por el hablante para facilitar la comprensión del sentido irónico. El concepto de tono irónico ${ }^{17}$ es un asunto complejo y que merece un buen trabajo de reflexión, pero no es descabellado pensar que la presencia en un texto oral o escrito de

17 Sobre este complejo tema, ver el trabajo de Padilla García «Enunciados irónicos en español: estudio fonopragmático». (en prensa). Un trabajo previo del mismo autor fue presentado en el 38 ." Congreso de la Societas Lingüística Europaea, Valencia, 7-11 de septiembre de 2005. bajo el título «Hablar con retintín o tono irónico». 
expresiones como «hablar como un libro», «gerifalte» 0 «lucirse» tengan la propiedad no sólo de ser interpretados ellos mismos como irónicos, sino de abrir al hablante la posibilidad de interpretar todo el texto o la intervención irónicamente, mientras que otras palabras o frases como «ser elocuente», «gobernante» 0 «hacer algo mal» no tienen, en principio, capacidad para activar esa posibilidad, y, por lo tanto, no dotan de tono irónico al enunciado en el que se encuentran. En definitiva y como señala Pierre Shoentjes (2003: 155) «Lejos de ser un asunto de inteligencia abstracta, el reconocimiento de la ironía es una cuestión de implicación con las realidades del mundo». Y es ahí donde radica la dificultad codificadora e interpretativa de la ironía, porque una ironía nace siempre de una situación comunicativa, de un intercambio lingüístico verbal en el que uno de los participantes decide, para comunicar su opinión, utilizar un procedimiento indirecto que, sin embargo, tiene la seguridad de que será comprendido por sus interlocutores. De lo que se trata es de saber cuánto le podemos pedir a un Diccionario —al DRAE en este caso- para ayudarnos a dilucidar los extremos de dicha implicación.

Así pues, en cuanto a las notas de uso, podemos decir que sólo nuestra competencia como hablantes de español nos permite adjudicar, con muchas dudas, en unas 24 ocasiones, el sentido irónico como sentido contrario. Se trata de «alhaja», «alhajita», «ancheta», «cromo», «despabilado», «don», «donosa», «espabilado», «lapidario», «lucirse», «perfeccionista», «rico», «sabido», «valiente» y de las expresiones fijas «coronar la fiesta», «irse al cielo calzado y vestido», «hablar como un libro», «llegar lejos», «por deporte», «de pata negra», «tocarle la lotería», «no tener precio», «ser buena finca», como en el ejemplo siguiente:

-A ver, señora ¿qué es la cosa?

-Pues que no hubo nada de aquellito.

Cómo de aquellito.

-Pues del casamiento de vusté con Silverita. El viejo se pasma y la vieja añade:

-Asina mesmo como se lo estoy diciendo; pero ni yo ni Rufo tenemos la culpa. Nosotros no somos gente de dos palabras.

— ¡Pero, señora, por Cristo! Cómo me sale, a estas horas, con semejante ancheta. ¿No se comprometieron, solemnemente, usted y Don Rufo, a darme la muchacha? Responda.

-Asina mesmo fue, Don José María; se lo prometimos de muy buena fe; pero...

Y en unas 15 el burlesco. En este último caso estarían, «cristianería», «ganga», «izquierdoso», «gerifalte», «mandamás», «speech», «tecnocracia» «en comandita», noli me tangere, «ciencia infusa», «haiga», «guardia pretoriana», «parafernalia», «piñonear» o «tecnocracia», de los que ofrecemos un par de ejemplos del CREA:

Quizás se insinúe aquí, más bien, una proclividad del cine venezolano a asociar la inteligencia con las carencias viriles, si recordamos al otro cobarde - además del lascivo delatorde Crónica de un subversivo latinoamericano, el pintor izquierdoso, o al siquiatra homosexual reprimido de Más allá del silencio (Miranda, Julio E. Palabras sobre imágenes. 30 años de cine venezolano, 1994)

También está siendo muy comentado lo de los hermanos Saura, Antonio y Carlos, hijos del director cinematográfico Carlos Saura. Y está siendo muy comentado porque dicen las lenguas de triple filo y de la madrugada que parece que toman todas las decisiones, incluso las amorosas, en comandita. ( $A B C, 16 / 06 / 1996$ : Rocío Jurado cantará en el hipódromo) 


\section{CONCLusiones}

Si de lo que se trata ahora es de extraer algunas conclusiones clarificadoras sobre cómo interpretar el sentido irónico en español a partir de la definición que del propio concepto da el DRAE y de la utilización que se hace de la marca a lo largo de la microestructura de éste, deberemos hacer algunas observaciones.

A lo largo de este trabajo creo que hemos podido comprobar que el Diccionario no nos ayuda demasiado a entender la ironía pues presenta diversidad y confusión de criterios en relación con el propio concepto. La primera evidencia de esta falta de criterio lo demuestra, por ejemplo, el hecho de que haya una clara discordancia entre el orden jerárquico en el que aparecen las acepciones en la definición -recordemos, burla fina y disimulada; tono burlón y dar a entender lo contrario- y los valores de su uso como mar$\mathrm{ca}$, pues mientras que en la definición se prima el concepto de burla, que es el que aparece en primer lugar desde la decimoquinta edición de 1925, el hecho es que del total de 153 marcas «irón.» que aparecen en el DRAE 2001, sólo unas 49 -un 32\%- se utilizan en este sentido, mientras que 92 -el $60 \%$ - se aplican con claridad a expresiones y palabras que, como ironías, significan lo contrario, acepción que, desde 1984, ocupa el tercer y último lugar. Este ambiguo criterio sobre la ironía — burla o antífrasis- unido a la falta de contextualización mediante ejemplos introducidos en los artículos es, en realidad, la clave del confuso concepto de sentido irónico que se aprecia en el DRAE. Como hemos podido observar, el problema se produce al ofrecer el DRAE idéntica marca a las palabras cuyo sentido irónico se justifica por expresar lo contrario de lo que se dice - sea esta la única acepción o sólo una de ellas- y a las palabras que suponen, en realidad, un procedimiento evaluativo en relación con la realidad nombrada. En este último grupo hemos encontrado palabras con connotaciones depreciativas e hiperbólicas mezcladas con un supuesto sentido irónico; en ningún caso significan lo contrario, pero la intención es decididamente burlesca, lo que si bien se ajusta a la primera acepción del término en el $D R A E$, resulta bastante desconcertante para el usuario, pues en ningún momento se hace alusión a la diferencia, que el Diccionario evidentemente maneja, entre ironía como sentido contrario e ironía como burla sarcástica.

Las notas de uso no son sino la prueba más fehaciente de este doble concepto de sentido irónico que se encuentra en el Diccionario, pero sobre todo, de la falta de un criterio claro para la adjudicación de la marca, pues el $D R A E$ no establece ninguna diferencia entre ambos procedimientos a pesar de que las consecuencias -en cuanto a la comprensión y uso de un enunciado como irónico- que se derivan de entender un sentido u otro son enormes.

Sería injusto, sin embargo, descargar toda la responsabilidad de este problema en la Lexicografía. Lo que realmente ha puesto en evidencia este trabajo no es otra cosa que la falta de un criterio linguístico fiable a partir del cual sea posible aplicar un concepto claro de ironía, dilucidar los mecanismos de lo irónico y establecer las clasificaciones y las tipologías que permitan entender y producir enunciados irónicos. La propia Pragmática carece de un concepto claro y de una propuesta resolutiva sobre el fenómeno de la ironía verbal. Los conceptos de eco o mención y las propuestas griceanas solucionan, como hemos apuntado, sólo parcialmente el problema del análisis de los enunciados irónicos, pues ni la ironía produce siempre un sentido contrario - a veces no es un eco de ninguna enunciación dicha o posible-, ni se resuelve el problema de las implicaturas en las 
ironías lexicalizadas. Por otra parte, la metapragmática asume como irónicas palabras modalizadas que, como hemos comprobado en el DRAE, ni son siempre estrictamente irónicas ni, realmente, se ajustan a ningún mecanismo de análisis que evidencien su ironía, pero, en todos los casos, dependen en última instancia, de las intenciones comunicativas de los hablantes.

Y es ahí donde radica la dificultad codificadora e interpretativa de la ironía, porque una ironía nace siempre de una situación comunicativa, de un intercambio linguístico verbal en el que uno de los participantes decide, para comunicar su opinión, utilizar un procedimiento indirecto que, sin embargo, tiene la seguridad de que será comprendido por sus interlocutores. Por eso es un asunto de la Pragmática y por eso la ironía no es un caso fácil. La ironía es un recurso universal, es el mejor aliado de estos seres parlantes que somos si, como escribe Jankelevitch (1982: 42), «los hombres hablan no tanto para hacerse entender como para esconderse». Intentar comprender qué mecanismos se ponen en funcionamiento en español para producir una ironía verbal, cómo reconocerla y analizarla, qué clases de enunciados irónicos manejamos en español, cómo enseñarlo a los hablantes no nativos son algunos de los retos que GRIALE se ha propuesto. Estudiar el sentido irónico en el $D R A E$ ha sido rico y clarificador porque ahora ya no hay duda sobre las dimensiones del reto. Y esto no es una ironía.

\section{BIBLIOGRAFÍA}

Albaladejo Mayordomo, Tomás. (1989): Retórica, Madrid, Síntesis.

AlBert Galera, Josefina (1996): «La pragmática en los diccionarios españoles actuales», en E. FORGAS (coord.), Léxico y diccionarios, Tarragona, Universitat Rovira i Virgili, pp. 7-23.

ALMANSI, Guido (1984): Amica ironia, Milan, Garzanti.

AZAuSTE, Antonio-CASAS, Juan (1997): La retórica en España, Barcelona, Ariel.

AZORÍN FERNÁNDEZ, Dolores (2000): Los diccionarios del español en su perspectiva histórica, Alicante, Universidad de Alicante.

Booth, Wayne C. (1989): Retórica de la ironía, Madrid, Taurus.

CASARES, Julio (1969): Introducción a la Lexicografía moderna, Madrid, CSIC.

CASAS, Elena (1980): La retórica en España. Madrid. Editora Nacional.

DíAZ-MingoYo, Gonzalo (1980): «El funcionamiento de la ironía», en Humor, ironía, parodia, Espiral. 7, pp. 45-68.

Diccionario de la Lengua española, Madrid, Real Academia Española, 2001 (versiones papel y CDROM).

DUCROT, Oswald. (1982): Decir y no decir, Barcelona, Anagrama.

ESCANDELL VIDAL, Victoria (2000): Introducción a la pragmática, Barcelona, Ariel.

FAJARDO A. (1996-97), «Las marcas lexicográficas: concepto y aplicación práctica en la Lexícografía espñola», Revista de Lexicografía, 3, 31-57.

GaRRIGA EsCRIBANO, Cecilio (1998): Las marcas de uso en el Diccionario de la Academia: evolución y estado actual, Tarragona, Universitat Rovira i Virgili.

GarRIGA EsCRIBano, Cecilio (1999): «El "registro familiar" como marca lexicográfica», en Díaz DE Revenga, Pilar y Jiménez Cano, José M. (eds.) Estudios de Sociolingüística II. Sincronía y diacronia, Murcia, DM, pp. 141-172.

GarRiga EsCRIBano, Cecilio (1996): «La marca irónico en el DRAE: de Autoridades a 1992», en E. FORGAS (coord.) Léxico y diccionarios, Tarragona, Universitat Rovira i Virgili, pp.105-131. 
GUTiÉRREZ J. (1996): «Las marcas en los diccionarios para extranjeros», en DíaZ DE REVENGA, Pilar y Jiménez Cano, José M. (eds.) Estudios de Sociolingüística, Murcia, DM, pp. 95-106.

HAENSCH, Günther, WOLF, L., ETTINGER, S. y WERnER, R. (1982 ): La Lexicografía. De la lingüistica teórica a la Lexicografía práctica, Madrid, Gredos.

HUTCHENS, Eleanor N., (1960): «The identification of Irony», Journal of English Literary History, $27,352-363$.

JANKELEVITCH, Vladimir (1982): La ironia, Madrid, Taurus.

KonX, Norman (1961): «The Word Irony and its Context: 1500-1755», Durham (North Carolina), Duke University Press.

KOTTHOFF, Helga (2003): «Responding to irony in different contexts: on cognition in conversation», Journal of Pragmatics, 35, 1387-1411.

LAUSBERG, Heinrich (1980): Manual de Retórica literaria, 3 vols., Madrid, Gredos.

LEECH, Geoffrey N. (1983): Principios de pragmática, Logroño, Universidad de La Rioja, 1997, traducción, notas y prólogo de Felipe Alcántara.

LEVINSON, Stephen C. (1983): Pragmática, Barcelona, Teide, 1989.

LÓPEZ EIRE, Antonio (1998): La retórica de la publicidad, Madrid, Arco.

LUJÁN ATIENZA, Ángel Luis (1999): Retóricas españolas del siglo XIX, Madrid, CSIC.

Mateu SERra, Rosa M. (1999): «El DRAE: algunas consideraciones para un posible enfoque pragmático», en Vila, N., Calero, M. Á.. Mateu, R. M, Casanova, M. y Orduña, J. L. (eds.) Así son los diccionarios, Lleida, Universitat de Lleida, pp. 203-219.

Mizzau, Marina (1984): Ironia. La contradizzione cossentita, Milán, Feltrinelli.

MOESCHLER, Jacques. \& ReBOUl, Anne (1999): Diccionario enciclopédico de pragmática, Madrid: Arrecife.

MUECKE, Douglas C. (1982): Irony and the Ironic, N. York, Methuen.

Padilla Garcia, Xose: «Enunciados irónicos en español: estudio fonopragmático» (en prensa)

PEnAdÉs MARTINEZ, Inmaculada (1999): «Para un tratamiento lexicográfico de las expresiones fijas irónicas desde la pragmática», Pragmalingüistica, 7, 1999, 185-210.

PENADÉs MARTINEZ, Inmaculada (2000): «Unidades fraseológicas del español con sentido irónico», en Englebert, A., Pierrard, M., Rosier, L. y Van Raemdonck, D. (eds.) Actes du XXIIe Congrès Internacional de Linguistique et de Philologie Romanes(Bruxelles, 1998), Tübigen, Verlag, vol. VII, pp. 575-581.

Pérez Lagos, Fernando (1999): «Diccionario y pragmática», en Alvar EzQuerra M., Corpas PasTOR, G. (coords.) Léxico y voces del español, Málaga, Universidad de Málaga, pp. 113-128.

QUiNTILIANO, Marco Fabio (1997): Institutionis oratoriae: libri XII, 4 vols., Salamanca, Universidad Pontificia de Salamanca (edición bilingüe).

REYES, Graciela (1990): La pragmática lingüística, Barcelona, Montesinos.

REYES, Graciela (2002): Metapragmática. Lenguaje sobre lenguaje, ficciones, figuras, Valladolid, Universidad de Valladolid.

Reyes, Graciela, Baena, E. y Urios, E. (2000): Ejercicios de pragmática I y II, Madrid, Arco.

Ruiz Gurillo, L.(2005): «La ironía verbal», en Hechos pragmáticos del español, Alicante, Universidad, Servicio de Publicaciones (en prensa).

Ruiz Gurillo, leonor, Marimón, C., Padilla, X. y Timofeeva, L. (2004): «El proyecto GRiale para la ironía es español: conceptos previos», ELUA, 18, 231-242.

SchoentJes, Pierre (2003): Poética de la ironia, Madrid, Cátedra.

Tesoro Lexicográfico de la lengua española, www.rae.es

TimofEeva, L. (2005): «La ironía en las unidades fraseológicas», Interlingüística, 16 (en prensa). TORRES SÁNCHEZ, M. Ángeles (1999): Aproximación pragmática a la ironia verbal, Cádiz, Universidad de Cádiz.

UTsumI, Akira (2000): «Verbal irony as an implicit display of ironic environment: Distinguishing ironic utterances from nonirony», Journal of Pragmatics, 32, 1777-1806. 